\title{
Analysis and Health Risk Assessment of Sodium Benzoate and Potassium Sorbate in Selected Fruit Juice and Soft Drink Brands in Nigeria
}

\author{
Asabe Mercy Magomya*, Gary Garbunga Yebpella, Ucheoma Chidinma Okpaegbe, \\ Odiba John Oko, Sunday Bature Gambo
}

Department of Chemical Sciences, Federal University, Wukari, Nigeria

Email address:

amagomya26@gmail.com (A. M. Magomya)

${ }^{*}$ Corresponding author

\section{To cite this article:}

Asabe Mercy Magomya, Gary Garbunga Yebpella, Ucheoma Chidinma Okpaegbe, Odiba John Oko, Sunday Bature Gambo. Analysis and Health Risk Assessment of Sodium Benzoate and Potassium Sorbate in Selected Fruit Juice and Soft Drink Brands in Nigeria. International Journal of Pharmacy and Chemistry. Vol. 6, No. 5, 2020, pp. 54-59. doi: 10.11648/j.ijpc.20200605.11

Received: September 2, 2020; Accepted: September 18, 2020; Published: October 7, 2020

\begin{abstract}
Sodium benzoate and potassium sorbate are chemical preservatives commonly used in fruit juice and soft drinks. In this study, a total of 20 commercial brands of such beverages in Nigeria were analysed for Sodium benzoate and Potassium sorbate using a UV-Vis spectrophotometric method. Preliminary validation of the method revealed good accuracy and precision; $94.54-97.25 \%$ mean recovery was recorded for benzoate and $92.7-96.82 \%$ for sorbate. $\%$ RSD for intraday precision was $1.67 \%$ and $2.36 \%$ for benzoate and sorbate respectively. The limits of detection and quantitation (LOD, LOQ) were $1.35,0.87 \mathrm{mg} / \mathrm{L}$ for sodium benzoate and $4.11,2.56 \mathrm{mg} / \mathrm{L}$ for potassium sorbate. The samples analysed all contained sodium benzoate in concentrations ranging from 25.80 to 245.10 while for potassium sorbate, fourteen samples tested positive with concentrations between $1.36-158 \mathrm{mg} / \mathrm{L}$. All the obtained concentrations for potassium sorbate were within acceptable limits but for sodium benzoate, seven samples were found with concentrations above permissible limits. Exposure estimation and health risk assessment carried out in this study revealed potential risks from the sodium benzoate content of some samples. The consumers that are prone to these risks are mainly children with body weights $\leq 30 \mathrm{~kg}$. Based on these findings, we recommend that the feeding of soft drinks and related beverages to children should generally be done with caution.
\end{abstract}

Keywords: Preservatives, Sodium Benzoate, Potassium Sorbate, Soft Drinks, Fruit Juice, Health Risks

\section{Introduction}

The use of chemical preservatives has become a very important practice in modern food technology. The key objective of preservatives in food is to impede chemical and microbial deterioration thereby increasing shelf life and maintaining quality. Commercial beverages often contain preservatives to prevent spoilage. Typically, sodium benzoate and/or potassium sorbate are the preservatives that are commonly used in fruit-based products and soft drinks. Both preservatives are often used in combination, especially in highly acidic drinks [1].

Sodium benzoate $\left(\mathrm{C}_{6} \mathrm{H}_{5} \mathrm{COONa}\right)$ is a preservative, with the E number, E211. It is mostly used in acidic foods such as carbonated drinks, jams and fruit juices. Under certain conditions $\mathrm{C}_{6} \mathrm{H}_{5} \mathrm{COONa}$ is converted into benzoic acid (E210), which is bacteriostatic and fungistatic. It exerts these properties by destroying the internal proton level of microbial cells [2]. Benzoic acid is generally not used directly due to its poor water solubility. The maximum permitted level for benzoates in soft drinks is $150 \mathrm{mg} / \mathrm{L}$, expressed as benzoic acid [3]. The Acceptable daily intake (ADI) for the preservative ranges from $0-5 \mathrm{mg} / \mathrm{Kg}$ body weight and the lethal dose (LD50) according to the European Food Safety Authority (ESFA), is $2000 \mathrm{mg} \cdot \mathrm{kg}^{-1}$ [4].

Potassium sorbate $\left(\mathrm{CH}_{3} \mathrm{CH}=\mathrm{CH}-\mathrm{CH}=\mathrm{CH}-\mathrm{CO}_{2} \mathrm{~K}\right)$, the potassium salt of sorbic acid is a popular food preservative (E202) that is used to inhibit molds and yeasts in many foods, such as cheese, wine, yogurt, apple cider, rehydrated fruits, soft drinks, fruit drinks, and baked goods [5]. The 
antimicrobial effectiveness of sorbates depends on the physical and chemical properties of the beverage. Sorbic acid affects yeast growth by inhibiting the uptake of amino acids and the function of sulfhydryl enzymes [2]. As a food additive, potassium sorbate is allowed in fruit juice and beverages at a concentration of $300 \mathrm{mg} / \mathrm{L}$ when used singly or $250 \mathrm{mg} / \mathrm{L}$ when used in combination with benzoates [3]. The acceptable daily intake (ADI) for potassium sorbate is 25 $\mathrm{mg} / \mathrm{kg}$ body mass or $1750 \mathrm{mg}$ daily for an average adult $(70$ $\mathrm{kg)} \mathrm{[6].}$

Although benzoic acid, sorbic acid and their salts (benzoate and sorbates) belong to a category of products generally recognized as safe (GRAs), excessive addition of these preservatives in food products may present adverse health effects to consumers. The development of allergic reactions to benzoate in humans, urticaria, metabolic acidosis, convulsions, hyperpnoea, weak clastogenic activity and asthma has been reported in some studies [7-11]. Benzoate can react with the ascorbic acid in drinks to produce benzene which is a known carcinogen [12]. Also, as a competitive inhibitor of D-amino acid oxidase, benzoate can influence neurotransmission and cognitive functioning [12]. One study indicated that benzoate can induce teratogenic effects during mouse fetal eye development [13]. Potassium sorbate is a skin, eye, and respiratory irritant in pure form. It has also been shown to have genotoxic activity in vitro under some conditions, particularly at high concentrations or when combined with nitrites [6].

Food related health effects and diseases are on the increase in both developed and developing countries. This necessitates the need for regular evaluation and assessment of commonly consumed food products in order to ensure their quality as well as their safety for human consumption. Since the consumption of soft drinks and non-alcoholic beverages is a widespread habit all around the world, such food products should be considered of great significance in terms of potential contribution to human health issues. The present research is aimed at investigating the levels of the preservatives; sodium benzoate and potassium sorbate in some brands of non-alcoholic beverages available in the Nigerian market. The determination of these additives is important for quality assurance purposes and consumer health protection. In addition, this study attempts an assessment of the human health risk that may result from consumption of the investigated beverages.

\section{Materials and Methods}

\subsection{Materials}

Sodium benzoate, potassium sorbate were purchased from Merck Co. (Darmstadt, Germany), Hydrochloric acid (Sigma-Aldrich) and petroleum ether was from CDH (India) All chemicals used were of analytical grade. A Shimadzu UVvisible spectrophotometer (UV-2450, Shimadzu, Japan) was used for all absorbance measurements.

\subsection{Sample Collection}

A total of 20 samples of non- alcoholic beverages were collected as representatives of what is typically found in the Nigerian market. Out of the 20 samples selected, 10 are fruit juice products while the other 10 are carbonated soft drinks. The fruit juice products were labelled as samples A to J while the soft drink samples were labelled $\mathrm{L}$ to $\mathrm{T}$.

\subsection{Preparation of Standards and Samples}

Individual standard stock solutions $\left(1000 \mathrm{mgL}^{-1}\right)$ of sodium benzoate and potassium sorbate were prepared in distilled water. Working standard solutions for each of the preservative were prepared by diluting the stock solutions appropriately with distilled water to give concentrations between $50 \mathrm{mg} \mathrm{L}^{-1}$ to $300 \mathrm{mg} \mathrm{L}^{-1}$. Hydrochloric acid $(0.4 \mathrm{~mL}, 6 \mathrm{M})$ were added to a $5 \mathrm{~mL}$ portion of each standard solution and then extracted with $45 \mathrm{~mL}$ Petroleum ether. For the samples, $0.4 \mathrm{~mL}$ of hydrochloric acid $(6 \mathrm{M})$ was added to $5.0 \mathrm{~mL}$ of each and then extracted with $45 \mathrm{~mL}$ petroleum ether in a separating funnel [14].

\subsection{Determination of Sodium Benzoate and Potassium Sorbate}

Sodium Benzoate and Potassium Sorbate were determined by means of a UV method described [15]. The absorbances of the standards prepared in 2.3 above were taken on a UV-Vis spectrophotometer at 227 and $250 \mathrm{~nm}$ (Pre-determined) for sodium benzoate and potassium sorbate respectively. Calibration graphs were plotted accordingly and the absorbances of the prepared samples were taken at the respective wavelengths for the analytes. Concentrations were determined by extrapolation from the calibration curves.

\subsection{Method Validation}

\subsubsection{Determination of Wavelength of Maximum Absorption}

Appropriate volumes of standard stock solutions of Sodium benzoate and Potassium sorbate were separately transferred into $10 \mathrm{ml}$ volumetric flasks and diluted to mark with distilled water to give $5 \mathrm{mg} / \mathrm{L}$ concentration. To determine the wavelengths for maximum absorption $\left(\lambda_{\max }\right)$, the standard solutions were scanned in the UV range of 200-400 nm using the diluent as blank.

\subsubsection{Accuracy}

Sample recovery was used to determine accuracy; Known amounts of Sodium benzoate and Potassium Sorbate were added to some pre- analysed sample solutions at different levels $(80 \%, 100 \%$, and $120 \%)$. The solutions were then re-analyzed and accuracy was estimated as percentage of preservatives recovered from the mixture.

\subsubsection{Precision}

Precision was studied as intraday variation; $100 \mathrm{mg} / \mathrm{L}$ solutions of Sodium benzoate and Potassium Sorbate were analysed five times in the same day and the relative standard deviation (RSD) for the measurements were taken as estimation of precision. 


\subsubsection{Sensitivity}

The sensitivity of measurements of was estimated in terms of the limit of quantification (LOQ) and limit of detection (LOD). The LOQ and LOD were calculated using the equations $\mathrm{LOD}=3.3 \times N / B$ and $\mathrm{LOQ}=10 \times N / B$, where ' $N$ ' is standard deviation of the peak areas of the drugs $(n=3)$, taken as a measure of noise, and ' $B$ ' is the slope of the corresponding calibration curve.

\subsection{Health Risk Assessment}

The health risk assessment for Sodium benzoate and Potassium sorbate in the investigated samples was done according to the method described by Caleshtori et al., [16] (with slight modifications). The daily consumption for ready to serve juice and carbonated soft drinks was estimated as 500 $\mathrm{mL} /$ day. Chronic daily intakes (CDI) of Sodium benzoate and Potassium sorbate for each sample were calculated as:

$$
\mathrm{CDI}=\mathrm{c} \times \mathrm{DI} / \mathrm{BW}
$$

Where; CDI is chronic daily intake for a consumer $(\mathrm{mg} / \mathrm{kg}$ body weight/day),

$\mathrm{c}$ is additive concentration $(\mathrm{mg} / \mathrm{L})$,

DI is Daily intake (L/day),

$\mathrm{BW}$ is body weight

To determine the significant exposure and overall potential for non-carcinogenic health effects by the additives (sodium benzoate and potassium sorbate), the target hazard quotient (THQ) was calculated using the equation:

\section{$\mathrm{THQ}=\mathrm{CDI} / \mathrm{RfD}$}

Where; CDI is chronic daily intake ( $\mathrm{mg} / \mathrm{kg} \mathrm{bw} /$ day) and $\mathrm{RfD}$ is reference dose $(\mathrm{mg} / \mathrm{kg}$ bw/day).

The RfD values used in this study were 4 and $25(\mathrm{mg} / \mathrm{Kg}$ bw/d) for Sodium benzoate and Potassium sorbate, respectively $[17,18]$.

A THQ value more than 1 (THQ $>1$ ) 1 indicates a significant risk level [19].

\section{Results and Discussions}

In this study, a UV spectrophotometric method was used for the determination of the preservatives sodium benzoate and potassium sorbate in fruit juice and soft drink samples. The method was first validated with respect to $\lambda \max$, linearity, precision, accuracy and sensitivity. These analytical parameters are presented in Table 1. The wave length for maximum absorption ( $\lambda$ max) was found to be $225 \mathrm{~nm}$ for sodium benzoate and $256 \mathrm{~nm}$ for potassium sorbate. The linear regression data for the calibration curves showed good linear relationship over the analysed concentration range (50-300 $\mathrm{mg} / \mathrm{L}$ ). For sodium benzoate, the linear regression equation was found to be $Y=0.0073 \mathrm{x}+0.1953$ with a correlation coefficient of 0.9923 and for potassium sorbate the regression equation was $Y=0.0113 \mathrm{x}+0.2269\left(\mathrm{R}^{2}=0.9968\right)$. The method indicated high precision as the RSD values for 5 replicate determinations (intraday) were $1.67 \%$ and $2.36 \%$ for sodium benzoate and potassium sorbate respectively. Mean recoveries for benzoate and sorbate were found to be $94.54-97.25 \%$ and $92.7-96.82 \%$ respectively $(n=5)$. This indicates that the method shows good accuracy for the determination of the preservatives. The sensitivity of the method evaluated in terms of limit of detection (LOD) and limit of quantitation (LOQ) revealed. 1.35 and $4.11 \mathrm{mg} / \mathrm{L}$ as LOD and LOQ values for sodium benzoate. For potassium sorbate the determined LOD and LOQ values were 0.87 and $2.65 \mathrm{mg} / \mathrm{L}$ respectively.

Table 1. Analytical characteristics of method.

\begin{tabular}{|c|c|c|}
\hline $\begin{array}{l}\text { Analytical } \\
\text { characteristics }\end{array}$ & Sodium benzoate & Potassium sorbate \\
\hline$\lambda \max$ & 225 & 256 \\
\hline Calibration equation & $\begin{array}{l}Y=0.0073 x+0.1953 \\
\left(\mathrm{R}^{2}=0.9923\right)\end{array}$ & $\begin{array}{l}Y=0.0113 x+0.2269 \\
\left(\mathrm{R}^{2}=0.9968\right)\end{array}$ \\
\hline $\mathrm{LOD}\left(\mathrm{mg} \mathrm{L}^{-1}\right)$ & 1.35 & 4.11 \\
\hline $\mathrm{LOQ}\left(\mathrm{mg} \mathrm{L}^{-1}\right)$ & 0.87 & 2.56 \\
\hline Precision (\%RSD) & 1.67 & 2.36 \\
\hline Accuracy (\% recovery) & $94.54-97.25$ & $92.7-96.82$ \\
\hline
\end{tabular}

Sodium benzoate and Potassium sorbate were found in varying amounts in the samples analysed in this study. The result of the analysis of fruit juice samples is presented in Table 2. All the fruit juice products contained sodium benzoate while eight (8) out of the ten (10) samples contained Potassium sorbate. The benzoate and sorbate concentrations ranged between $25.80-245.10 \mathrm{mg} / \mathrm{L}$ and $1.36-85.54 \mathrm{mg} / \mathrm{L}$ respectively. The determination of the preservatives in carbonated soft drinks revealed a concentration range of $14.25-218.32 \mathrm{mg} / \mathrm{L}$ for benzoate and $2.22-158.0$ $\mathrm{mg} / \mathrm{L}$ for sorbate (Table 3). Our findings show that all the analysed samples were positive for at least one of the preservatives investigated. The most prevalent however was benzoate as all the samples were positive for it.

A limit of $150 \mathrm{mg} / \mathrm{L}$ and $300 \mathrm{mg} / \mathrm{L}$ have been set for benzoate (benzoic acid) and sorbate (sorbic acid) respectively, if they are found separately in packaged drinks and 150 and $250 \mathrm{mg} / \mathrm{L}$ if they are found together in a particular drink [3]. Our results show that three fruit juice brands (samples B, D and H) and four soft drink brands (L, M, R and T) contain sodium benzoate above the permissible limit. The sorbate concentrations obtained in this study were all less than $250 \mathrm{mg} / \mathrm{L}$ therefore are within acceptable limits. Overall, only sodium benzoate was found above permissible limits in some of the analysed samples and this category represents $35 \%$ of the total samples investigated.

Table 2. Determination of Sodium benzoate and Potassium Sorbate in fruit juice samples.

\begin{tabular}{lll}
\hline $\begin{array}{l}\text { Sample } \\
\text { code }\end{array}$ & $\begin{array}{l}\text { Concentration of Sodium } \\
\text { benzoate }(\mathbf{m g} / \mathbf{L})\end{array}$ & $\begin{array}{l}\text { Concentration of } \\
\text { Potassium sorbate }(\mathbf{m g} / \mathbf{L})\end{array}$ \\
\hline A & $96.42 \pm 1.74$ & $65.24 \pm 2.04$ \\
B & $212.56 \pm 4.82$ & $6.55 \pm 1.84$ \\
C & $132.05 \pm 3.44$ & $15.75 \pm 1.58$ \\
D & $245.10 \pm 2.96$ & $1.36 \pm 0.85$ \\
E & $116.41 \pm 1.74$ & $2.40 \pm 0.12$ \\
F & $75.56 \pm 2.25$ & $35.28 \pm 3.20$ \\
G & $25.80 \pm 1.74$ & $122.50 \pm 5.25$ \\
H & $196.65 \pm 6.40$ & ND \\
I & $46.33 \pm 2.85$ & ND \\
J & $96.42 \pm 1.74$ & $85.54 \pm 4.08$ \\
\hline
\end{tabular}


Table 3. Determination of Sodium benzoate and Potassium Sorbate in carbonated Soft drinks.

\begin{tabular}{lll}
\hline $\begin{array}{l}\text { Sample } \\
\text { code }\end{array}$ & $\begin{array}{l}\text { Concentration of sodium } \\
\text { benzoate }(\mathbf{M g} / \mathbf{L})\end{array}$ & $\begin{array}{l}\text { Concentration of } \\
\text { Potassium sorbate }(\mathbf{M g} / \mathbf{L})\end{array}$ \\
\hline K & $102.54 \pm 3.14$ & ND \\
L & $182.21 \pm 6.45$ & ND \\
M & $174.80 \pm 5.76$ & ND \\
N & $65.32 \pm 1.68$ & $16.55 \pm 1.56$ \\
O & $14.25 \pm 2.55$ & $158 \pm 2.60$ \\
P & $56.52 \pm 1.84$ & $111.3 \pm 3.76$ \\
Q & $126.60 \pm 3.28$ & ND \\
R & $218.32 \pm 0.72$ & $78.6 \pm 6.50$ \\
S & $161.20 \pm 2.32$ & 35.45 \\
T & $142.4 \pm 5.22$ & $2.22 \pm 1.06$ \\
\hline
\end{tabular}

The levels of preservatives obtained in this study have been compared with values reported from similar studies in other countries (Figures 1 and 2). An evaluation of the levels of preservatives in certain food stuffs in Iran [20] revealed average benzoate concentration of $103.2 \mathrm{ppm}$ in soft drinks with a range of $83.2-125.0 \mathrm{ppm}$. The mean value reported here is slightly lower than what we report in the current study which is $114.42 \mathrm{ppm}$. A study on the levels of benzoic acid in Soft Drinks and fruit Juices sold in Ghana [21] recorded mean benzoate concentrations of $70.20 \mathrm{mg} / \mathrm{L}$ and 31.00 $\mathrm{mg} / \mathrm{L}$ for soft drinks and fruit juice samples respectively. These values are lower than what was obtained in our current study. Levels of Sodium benzoate $(151.76$ - 190.04 ppm) higher than the current study have been recorded in a study carried out on Bangladesh soft drinks [22]. Similar studies in India [23] and Srilanka [24] also recorded much higher levels of benzoate than this study; the reported values were 172.35 - 396.44 and 33 - 631ppm respectively. Concentrations of benzoate ranging from 1.03 to $60 \mathrm{ppm}$ have been reported for soft drinks and related beverages sold in Pakistan [25]; these values are much lower than what we report in this study.

Varying levels of Potassium sorbate in soft drinks and fruit juices have been recorded by different researchers across the globe. Figure 2 presents a comparison of the concentrations obtained in this study with some reported values from literature. Sorbate concentration ranging from 1.2 - $316.6 \mathrm{ppm}$ was recorded for a study in Iran [26]. Another Study in Iran reported $<1.5-233.33$ ppm reported for fruit juice and soft drinks [20]. Sorbic acid levels in carbonated beverages, jelly drinks and ready to serve soft drinks in Sri lanka have been shown to range from $23-582$ ppm [24]. These values are higher than the $1.3-158 \mathrm{ppm}$ range recorded in this study. Higher sorbate levels than our present study have also been reported for a study carried out in Lagos, Nigeria [27]; their obtained concentration ranged from 1.15 - $499 \mathrm{ppm}$. A study in Chennai, India also recorded higher potassium sorbate levels than the current study [28]; the reported values ranged from $120-562 \mathrm{ppm}$. A study carried out in Pakistan [25] showed no potassium sorbate in the soft drinks and fruit juice samples analysed. Our findings from literature suggest that sodium benzoate is a more preferred preservative than potassium sorbate for use in soft drinks and related beverages.

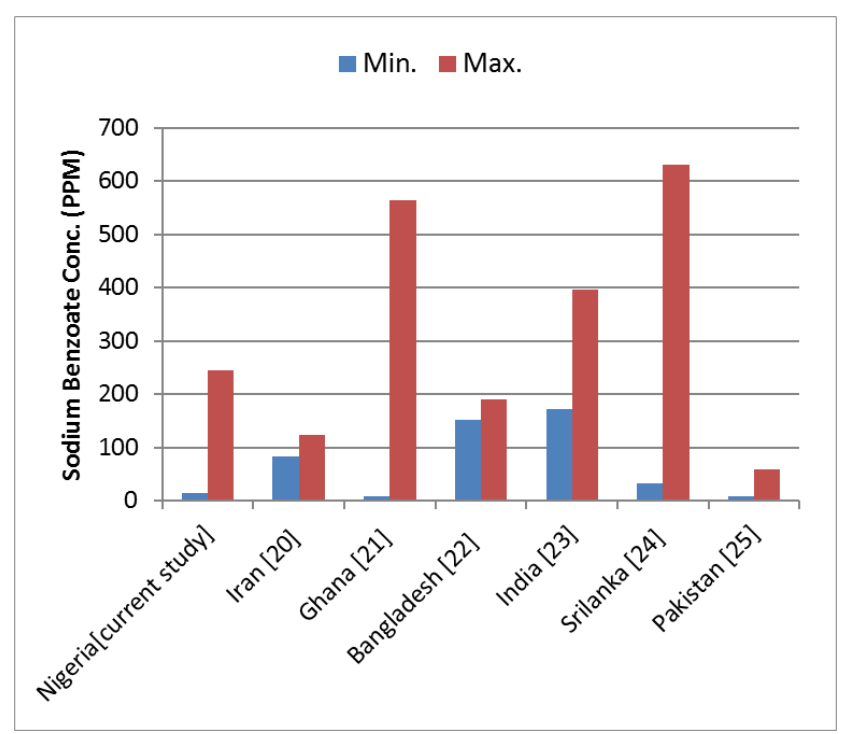

Figure 1. Comparison of Sodium Benzoate levels in Current study with other Studies from Literature.

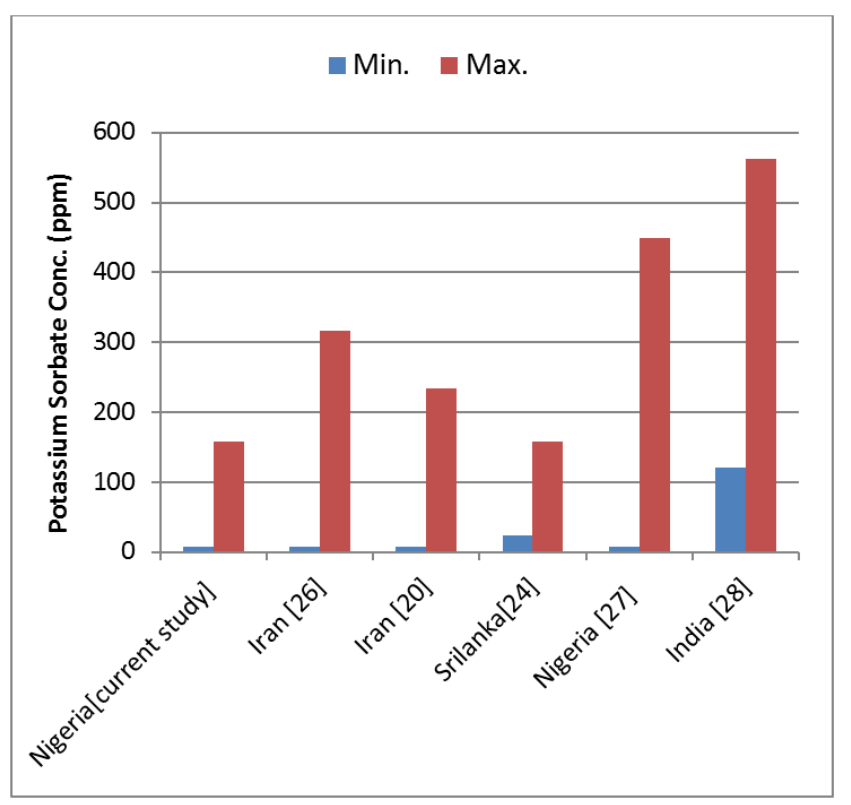

Figure 2. Comparison of Potassium Sorbate levels in Current study with other Studies from Literature.

The exposure estimation and health risk assessment of the preservatives (Sodium benzoate and potassium sorbate) as evaluated from the beverages analysed are presented in Tables 4 and 5. The assessments were made under the assumption that $50 \mathrm{cl}(500 \mathrm{ml})$ is taken daily. For sodium benzoate (Table 4 ), the chronic daily intake (CDI) ranged from $0.1-12.26$ $\mathrm{mg} / \mathrm{kg}$ bw/day for the different body weights considered in this study. The Acceptable daily intake (ADI) for benzoates ranges from $0-5 \mathrm{mg} / \mathrm{kg}$ bw. From our assessments, it can be seen that the ADI would be exceeded from consumption of some of the investigated brands by persons within $10-20 \mathrm{~kg}$ body weights. The total hazard quotient (THQ) evaluated for sodium benzoate ranged from 0.02 to 3.03 . A THQ value more than $1(\mathrm{THQ}>1)$ shows a significant risk level and the higher the value, the greater the likelihood of adverse 
non-carcinogenic health impact [19]. Our results here show that the categories that would most likely face significant risks are those with weights $\leq 30$. These categories are usually children within the ages of 2 to 10 years. A total of 14 out of the 20 investigated samples could therefore be considered as unsafe for consumption by children.

The assessment for potassium sorbate (Table 5) revealed CDI values between $0.009-7.9 \mathrm{mg} / \mathrm{kg}$ bw/day and THQ from $0.0003-0.32$. The low THQ values obtained here are a reflection of the relatively low levels of sorbate obtained in the investigated samples and also the high ADI of potassium sorbate which is $250 \mathrm{mg} / \mathrm{kgbw}$. Since all the THQ values are lower than 1 , it can be concluded that no significant health risk would result from the sorbate contents of the beverages under consideration. It should be noted however that even samples with low THQ can present health risks when other food sources of the preservatives are consumed; the intakes from all food sources would contribute to elevating the daily hazard index (HI) which is the sum of THQs from all ingested foods.

Table 4. Exposure estimation and Health risk assessment of Sodium Benzoate in Fruit juice and soft drinks samples.

\begin{tabular}{llll}
\hline Consumer body weight $(\mathbf{K g})$ & CDI $(\mathbf{m g} / \mathbf{k g}$ bw/day) & THQ & No. of Samples with THQ>1 \\
\hline 10 & $0.71-12.26$ & $0.73-3.03$ & 14 \\
20 & $0.36-6.18$ & $0.6-1.55$ & 8 \\
30 & $0.24-4.08$ & $0.06-1.02$ & 1 \\
40 & $0.18-3.06$ & $0.05-0.77$ & 0 \\
50 & $0.14-2.45$ & $0.03-0.61$ & 0 \\
60 & $0.12-2.04$ & $0.03-0.5$ & 0 \\
70 & $0.10-1.75$ & $0.02-0.43$ & 0 \\
\hline
\end{tabular}

Calculation was based on the assumption that $500 \mathrm{ml}$ is taken each day.

$\mathrm{BW}=$ bodyweight, $\mathrm{CDI}=$ Chronic daily intake, $\mathrm{THQ}=$ Total hazard quotient.

Table 5. Exposure estimation and Health risk assessment of Potassium sorbate in Fruit juice and soft drinks samples.

\begin{tabular}{llll}
\hline Consumer body weight $(\mathbf{K g})$ & CDI $(\mathbf{m g} / \mathbf{k g}$ bw/day) & THQ & No. of Samples with THQ>1 \\
\hline 10 & $0.068-7.9$ & $0.03-0.32$ & 0 \\
20 & $0.034-3.95$ & $0.001-0.16$ & 0 \\
30 & $0.02-2.6$ & $0.001-0.1$ & 0 \\
40 & $0.017-1.98$ & $0.001-0.08$ & 0 \\
50 & $0.014-1.58$ & $0.0005-0.06$ & 0 \\
60 & $0.011-1.32$ & $0.0004-0.05$ & 0 \\
70 & $0.009-1.13$ & $0.0003-0.05$ & 0 \\
\hline
\end{tabular}

Calculation was based on the assumption that $500 \mathrm{ml}$ is taken each day.

$\mathrm{BW}=$ bodyweight, $\mathrm{CDI}=$ Chronic daily intake, $\mathrm{THQ}=$ Total hazard quotient.

\section{Conclusion and Recommendations}

The current study shows the presence of sodium benzoate and potassium sorbate in some soft drinks and fruit juice products marketed in Nigeria. Among the two preservatives, Sodium benzoate appears to be more preferred by producers in the country. The levels of the preservatives in the samples investigated were mostly within acceptable limits; $100 \%$ and $65 \%$ safe levels were recorded with respect to potassium sorbate and sodium benzoate respectively. Although most of the analysed brands can be labelled as safe with respect to allowed levels of the preservatives, the risk assessment carried out indicated that $70 \%$ of the samples could present health risks to children with body weights $\leq 30 \mathrm{~kg}$. In view of this, we recommend that the feeding of commercial fruit juices and soft drinks to children should generally be minimised or avoided. Regular testing and safety evaluation of additives in soft drinks and related beverages is highly recommended because soft drinks are among the most consumed products globally. Worldwide, the soft drinks market consumes about 392 billion litres yearly and this quantity is said to be growing by $5 \%$ each year [29]. The relevance of such beverages in food safety issues can therefore not be over emphasised. There is need for risk assessments of additives to be undertaken to an increased extent globally in order to establish better regulations for the protection of human health.

\section{References}

[1] UNESDA http://www.unesda.eu/lexikon/preservatives/.

Preservatives,

[2] Battey, A. S., Duffy, S. and Schaffner, D. W (2002). "Modeling yeast spoilage in cold-filled ready-to-drink beverages with Saccharomycescerevisiae, Zygosaccharomyces bailii, and Candida lipolytica," Applied and Environmental Microbiology, 68 (4): 1901-1906.

[3] WHO (World Health Organization), (2000). Evaluation of Certain Food Additives (Fifty first Report of the Joint FAO/WHO Expert Committee on Food Additives).

[4] European food Safety Authority (EFSA) Regulation (2017). Regulation 1333/2008. Available at: http://www.fao.org/food/food-safetyquality/scientific-advice/j ecfa/en/.

[5] AAFCO (2004). "Official Publication": 262). 
[6] Carocho, M., Barreiro, M., Morales, P. and Ferreira I. C. F. R. (2014). Adding molecules to Food, Pros and cons: Areview on synthetic and natural additives. Comprehensive Reviews in Food Sci. and food safety 13 (4): 377-399.

[7] Tfouni, S. A. V. and Toledo, C. F. (2002). Determination of benzoic and sorbic acids in Brazilian foods. Food control. 13: 117-123.

[8] Jahed, K. R. (2007). Chemical contaminants in milk and public health concerns: A review. International Journal of Dairy science 2 (2): 104-115.

[9] Wen, Y., Wang, Y. and Feng Y. Q. (2007). A simple and rapid method forsimultaneous determination of benzoic and sorbic acids in food using in-tube solid-phase microextraction coupled with high-performance liquid chromatography. Anal Bioanal Chem. 388: 1779-1787.

[10] Santini, A. O., Pezza, H. R., Filho, J., Sequinel, R. and Pezza, L. (2009). Potentiometric sensor for sorbic acid determination in food products. Food Chemistry 115 (4): 1563-1567.

[11] Lino, C. M. and Pena, A. (2010). Occurrence of caffeine, Saccharin, benzoic acid and sorbic acid in soft drinks and nectars in Portugal and subsequent exposure assessment. Food Chemistry 121 (2): 503-508.

[12] Piper J. D. and Piper, P. W. (2017). Benzoate and Sorbate Salts: a systematic review of the potential hazards of these invaluable preservatives and the expanding spectrum of clinical uses for sodium benzoate. Compr. Rev. Food Sci. Food Saf. 16: 868880 .

[13] Afshar, M., Moallem, S. A., Khayatzadeh, J. and Shahsavan, M. (2013). Teratogenic effects of long term consumption of potassium benzoate on eye development in Balb/c fetal mice. Iran J Basic Med Sci 16 (4): 593-8.

[14] Reddy, M. V., Aruna, G., Parameswari, S. A., Banu, B. H. And Reddy, P. J (2015) Estimated daily intake and exposure of sodium benzoate and potassium sorbate through food products in school children of Tirupati, India. Int J Pharm Pharm Sci, 17 (7): 129-133.

[15] Mahboubifar, M., Sobhani, Z., Dehghanzadeh, G. and Katayoun Javidnia, K. (2010). Comparison between UV Spectrophotometer and High-performance Liquid Chromatography Method for the Analysis of Sodium Benzoate and Potassium Sorbate in Food Products. Food Anal. Methods 12161-010-9158-0.

[16] Chaleshtoria, F. S., Arianb, A. and Chaleshtoric, R. S. (2018). Assessment of sodium benzoate and potassium sorbate preservatives in some products in Kashan, Iran with estimation of human health risk Food and Chemical Toxicology 120 (2018) 634-638.

[17] European Union, 2012. Regulation (EU) No 528/2012 of the European Parliament and of the Council of 22 May 2012 concerning the making available on the market and use of biocidal products. Off. J. Eur. Union L. 167, 1-16.
[18] Mischek, D. and Krapfenbauer-Cermak, C. (2012). Exposure assessment of food preservatives (sulphites, benzoic and sorbic acid) in Austria. Food Addit Contam Part A Chem Anal Control Expo Risk Assess. 29 (3): 371-82.

[19] Alif Adham, Z. and Shaharuddin, M. (2014). Nitrate levels in groundwater and health risk assessment in three villages in Pasir Puteh, Kelantan. Health Environ. J. 5, 139-148.

[20] Amirpour, M., Arman, A., Yolmeh, A., Azam, M. A. and Moradi-Khatoonabadi, Z. 2015. Sodium benzoate and potassium sorbate preservatives in food stuffs in Iran. Food Additives and Contaminants Part B Surveillance 8 (2): 142. 148.

[21] Kusi, J. K. and Acquaah, S. O (2014). Levels of Benzoic Acid in Soft Drinks and Fruit Juices in Ghana. IOSR Journal of Environmental Science, Toxicology and Food Technology 8: (12) 36-39.

[22] Sultana, A., Islam, R., Islam, M., Shoeb, M and Nahar, N. (2016) Study of Preservatives and Stimulants in Commercial Soft Drinks. Bangladesh Pharmaceutical Journal 19 (1): 68-74.

[23] Lakshmi, N. V and Anoop, A. (2019). Study and Quantification of Preservative (E211) In Carbonated Soft Drink Samples. IOSR Journal of Applied Chemistry (IOSR-JAC) 12 (4): 17.

[24] Karunarathne, K. (2019). Levels of Benzoic and Sorbic Acid Preservatives in Commercially Produced Ready to Serve Products in Sri Lanka. Acta Scientific Pharmaceutical Sciences 3 (8): 02-07.

[25] Ahmed, M., Shahzadi, S. K., Waseem, R., Shahzad, S. and Ahmad, W. (2013). Sodium benzoate and potassium sorbate in Pakistani retail foodstuffs. Int. J. Chem. Sci. Res. 3: 1-6.

[26] Khosrokhavar, R., N. Sadeghzadeh, N., Amini, M., Ghazi-Khansari, M., R. Hajiaghaee, and Ejtemaei, M. S (2010). Simultaneous determination of preservatives (Sodium Benzoate and Potassium Sorbate) in soft drinks and herbal extracts using high- performance liquid chromatography (HPLC), Journal of Medicinal Plants, 9 (35: 2010, 80-87.

[27] Ogunleye, D. T, Oyeyiola, A. O, Onwordi, C. T, Falana, T. G and Abolade O. M (2017). Spectrophotometric and high performance liquid chromatograhic determination of sodium benzoate and potassium sorbate in some soft drinks. Unilag Journal of Medicine, Science and Technology (UJMST) 5 (1): $168-178$.

[28] Sneha, S. and Preetha, R. (2015). Determination of sodium benzoate $\&$ potassium sorbate contamination in ready to serve products in post market surveillance in Chennai Discovery, 51 (240): 176-183.

[29] http://www.sleever.com/trends/solution/juices-and-soft-drinks. 